\title{
Optimal Selection of Overseas Oil Development Projects of Sinopec Based on a Multi-Objective Programming Model $^{*}$
}

\author{
Haijun Fan', Xueqian Zhu², Guangchao Li², Yumei Fan² \\ ${ }^{1}$ China University of Petroleum, Qingdao, China \\ ${ }^{2}$ Sinopec Institute of Petroleum Exploitation and Development, Beijing, China \\ Email: petroengineer@126.com
}

How to cite this paper: Fan, H.J., Zhu, X.Q., Li, G.C. and Fan, Y.M. (2018) Optimal Selection of Overseas Oil Development Projects of Sinopec Based on a Multi-Objective Programming Model. Open Journal of Social Sciences, 6, 1-11. https://doi.org/10.4236/jss.2018.63001

Received: November 3, 2017

Accepted: March 10, 2018

Published: March 13, 2018

\begin{abstract}
With the continuous low oil price, the national oil companies in China are under the pressure of lowering the development cost and improving their investment efficiency of their overseas investments. Optimal methods are needed in screening the overseas assets within the constraint of investment. This paper presents a multi-objective integer programming model for the optimal selection of overseas oil development projects for Sinopec based on the economic evaluation of various projects in different countries and regions. Combination of economic parameters and practical constraints are discussed and presented in the mathematical models. Application of the model shows its advantages over the traditional screening and ranking methods.
\end{abstract}

\section{Keywords}

Oil Development Project, Optimal Selection, Sinopec, Multi-Objective Model

\section{Introduction}

In recent years as one of the major Chinese NOCs, China Petroleum \& Chemical Corporation (Sinopec) have emerged as significant players in global mergers and acquisitions in upstream oil and natural gas for the need of domestic economic development. After years of expanding and diversifying its overseas reserves, Sinopec has made significant improvement in its overseas production levels. In 2016, Sinopec spent USD 29.39 billion approximately for the assets outside China, with more than half located in the Middle East and Africa. All of overseas reserves are under the management of Sinopec International Petroleum Explora-

${ }^{*}$ Sponsored by China National Science and Technology Major Project (2016ZX05033005-008). 
tion and Development Corporation (“SIPC"), a wholly-owned subsidiary of Sinopec Group, which specialized in overseas oil and gas investment and operations. Under the pressure of low oil price, SIPC is seeking to reduce overseas investment and improve the management efficiency of overseas assets by lowering non-efficient overseas output, driving down operational costs of overseas oil and gas production and slashing management fees.

The management of overseas projects of Sinopec is under a three-level structure, Company-Asset-Project, as in Figure 1. SIPC is on the top and has the final decision. Each asset under the SIPC owns different projects with different contracts, components, life time, or even different oil prices, all evaluated with cash flow model. The objectives of SIPC to reduce the expense and improve investment efficiency are realized by expanding or keeping good project and cutting or suspending the poor projects. This cannot be reached simply by selecting projects according to the economic indexes, such as NPV or PIR. Mean while at different level there are also other requirements or limitations, for instance SIPC may not want to abandon a whole asset or in one asset some existing projects should be kept because of mutual obligations. So in this paper a multi-objective programming model is presented considering all of the requirements and obligations under some limitation of capital expenditure or oil production.

\section{Literature Review}

Aronofsky (1983) [1] summarized the use of linear programming (LP) and Mixed Linear Programming (MIP) in the optimization of oilfield development, especially the combination of LP with reservoir simulation.

Modern portfolio theory [2] was introduced into petroleum ventures by many researchers [3] [4] [6] [7]. Hightower (1991) adopted a modified Markowitz portfolio model utilizing the semi-variance risk parameter to meet the investment objectives and information limitations characteristic of the oil industry.

Campbell (1999) [5] reviewed the limitation of traditional discounted cash flow (DCF) analysis and present two new approaches to measuring value for long-term

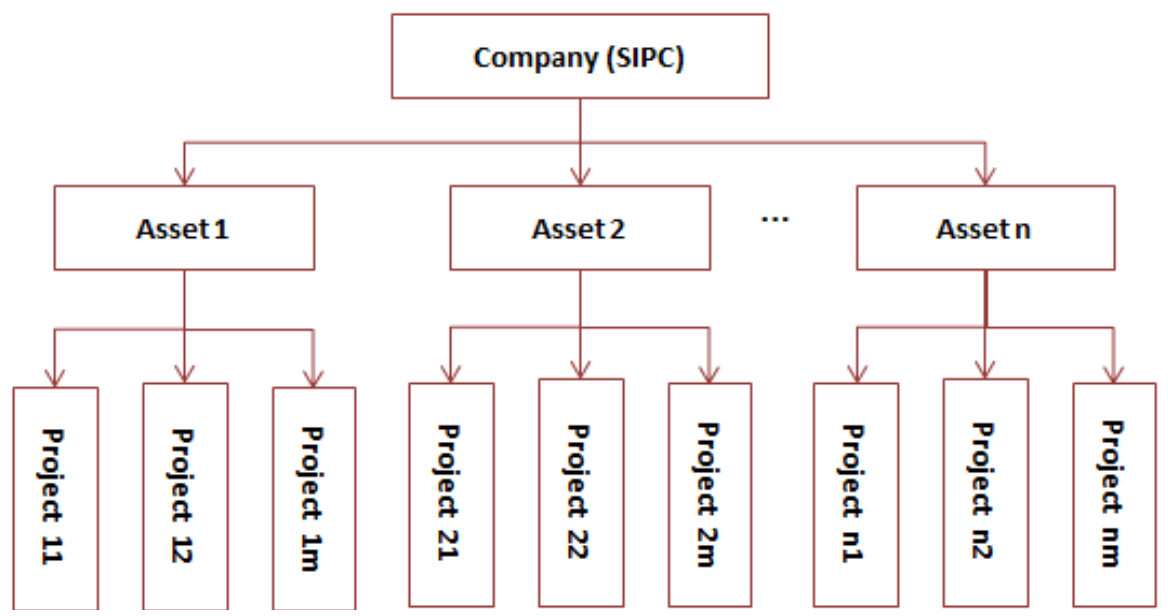

Figure 1. Asset hierarchy of Sinopec overseas projects. 
and strategic projects, called Strategic Diversification Value (SDV) and Venture Capitalist Value (VCV) respectively. The SDV implies a changing discount rate after the discounted payback is reached. With VCV, the emphasis shifts to measuring the cash flow through an amortization schedule for returning investment capital rather than focusing on discounting.

L. G. Chron (2004) [6] describes the application of dynamic programming techniques and the concepts of Markov chains to modeling projects within an investment opportunity portfolio. By dividing the investment opportunity set as exploration portfolio and development portfolio he treat the assets in the portfolio as dynamic opportunities requiring irregularly timed investments and yielding rewarding on multiple dimensions.

Rasey (2005) [7] presents a portfolio optimization method using visualization which gives the decision maker new abilities to manage a portfolio of investment opportunities instead of building LP models. Morteza (2010) [8] provides a simple approach to assess alternative projects and help the decision maker to select the best one for National Iranian Oil Company by using six criteria of comparing investment alternatives as criteria in an AHP and fuzzy TOPSIS techniques.

Zhong [9] use Data Envelopment Analysis (DEA) to present a method to determine the optimal scale of productivity construction investment in unit production. He established an optimal model with net present value (NPV) as objective function and constraints including investment, reserve/production ratio, production and some equality constraints.

Tang et al. (2017) [10] analyzed investment opportunity of an oil field project located in Kazakhstan by combining discounted cash flow method and the trinomial tree model of real option approach (ROA) considering uncertainties such as oil price, exchange rate and political environment.

The Sinopec overseas development projects in different countries and regions are under different reservoir types, lifetime, different operators and even different production share contracts. Not all of the projects are conducted probabilistic assessments or EMV evaluation based on some mathematical methods such as Monte Carlo. The normally adopted oilfield asset management theory that involves reservoir simulation and implementation of development plan is hardly used either when there is no reliable detailed geological model available, on the other hand it is time-consuming and unnecessary to involve the well location and control strategies for projects selection. So based on the current deterministic economic evaluation of different projects and other available project information, we present a multi-objective programming model for the optimal selection of overseas projects.

\section{Theoretical Model}

To select the most efficient and profitable combination among petroleum development projects under some kind of investment constraints is highly like Knapsack Problem, which belongs to NP-hard problem. To invest a project or 
not means the value of decision variables should be 0 or 1 . So it is actually a 0 - 1 Knapsack Problem or a general Integer Programming (IP) Problem.

The general mathematical expression of multi-objective linear programming model can be written as (1),

$$
\begin{aligned}
& \max Z=C x \\
& \text { s.t. }\left\{\begin{array}{l}
A x \leq b \\
x \geq 0
\end{array}\right.
\end{aligned}
$$

in which

$$
\begin{aligned}
& x=\left(x_{1}, x_{2}, \cdots, x_{n}\right)^{T}, \quad Z=\left(z_{1}, z_{2}, \cdots, z_{r}\right)^{T}, \quad A=\left(a_{i j}\right)_{m \times n}, \quad C=\left(c_{i j}\right)_{r \times n}, \\
& b=\left(b_{1}, b_{2}, \cdots, b_{m}\right)^{T}
\end{aligned}
$$

If the value of decision variable $\mathrm{x}$ can only be 0 or 1 , it is also called a $0-1$ programming problem.

As mentioned in the introduction, in the three-level management structure of Sinopec overseas investments, all of the projects in each asset are economically evaluated based on cash flow model. All of the economic parameters are known for each project. Ten economic indices have been selected as the combination of objective function as list in Table 1.

The objective function in the model is a combination of the above economic parameters at different weights. For instance, if we take NPV, PIR and UOC as multi-objective function, the model can be expressed as:

$$
\operatorname{Max} \sum_{j=1}^{m} \sum_{i=1}^{n_{j}}\left\{w_{1}(N P V)_{i j} x_{i j}+w_{2}(P I R)_{i j} x_{i j}-w_{3}(U O C)_{i j} x_{i j}\right\}
$$

where

$(N P V)_{i j}$ is the normalized NPV of Project $i$ in Asset $j$,

$(P I R)_{i j}$ is the normalized PIR of Project $i$ in Asset $j$,

Table 1. Economic parameters used as objectives.

\begin{tabular}{ccccc}
\hline ID & Objective Indices & Unit & Economic Meaning & Importance \\
\hline 1 & NPV & MM\$ & Net Present Value & $\star \star \star \star \star$ \\
2 & NAV & MM\$ & Net Annual Value & $\star \star \star \star$ \\
3 & PROD & MMBOE & Equivalent oil production & $\star \star \star$ \\
4 & CAPEX & MM\$ & Capital Expenditure & $\star \star$ \\
5 & PIR & & Profit investment ratio & $\star \star \star \star \star$ \\
6 & UTC & \$/BOE & Unit total cost & $\star \star \star \star \star$ \\
7 & UDC & \$/BOE & Unit Development cost & $\star \star \star \star$ \\
8 & UOC & \$/BOE & Unit operation cost & $\star \star \star \star$ \\
9 & Netprofit & MM\$ & Net profit & $\star \star \star \star \star$ \\
10 & ROCE & & Return on Capital Employed & $\star \star \star \star$ \\
\hline
\end{tabular}


$(U O C)_{i j}$ is the normalized UOC of Project $i$ in Asset $j$,

$w_{1}, w_{2}, w_{3}$ is the weight for objective NPV, PIR and UOC.

$x_{i j}$ is the decision variable, the value is 0 or 1 , which mean rejected or selected respectively.

In the ten objectives, for a determined selection of projects, the ROCE can be expressed as:

$$
\text { ROCE }=\frac{\sum_{j=1}^{m} \sum_{i=1}^{n_{j}}(\text { Profit })_{i j} x_{i j}}{\sum_{j=1}^{m} \sum_{i=1}^{n_{j}}(\text { Capex })_{i j} x_{i j}}
$$

So if ROCE is included in the objective function, it will become a nonlinear integer programming problem.

To realize the goals of keeping good projects, cutting or suspending the poor projects, the first constraint is investment limit. An appropriate Capex limitation should be given for the whole company (SIPC) or for an individual asset. Other constraints may include the oil production should be greater than some required value, the net profit should be positive or the ROCE should be great than some value to maintain a minimum capital efficiency. The main constraints are list in

\section{Table 2 .}

It should also be noticed that if ROCE is included in constraints, it will become a nonlinear integer programming problem. Nonlinear algorithm such as Genetic Algorithm may be needed in solving the problem.

In order to avoid cutting all of the projects in one asset, the following option can be given in the model.

$$
\sum_{i=1}^{n_{j}} x_{i j}>0 \quad(j=1,2, \cdots, m)
$$

To gain better access to crucial technical and managerial know-how in areas in which Sinopec are relatively inexperienced, the company would like to keep a proportion of unconventional oil and gas assets in the total investments. This constraint can be expressed as:

$$
\frac{\sum_{j=1}^{m} \sum_{i=1}^{n_{j}} H(x) x_{i j}}{\sum_{j=1}^{m} \sum_{i=1}^{n_{j}} x_{i j}} \geq b_{\text {unconv }}
$$

Table 2. Main constraints in the optimization model.

\begin{tabular}{ccc}
\hline Constraint & Expression & Description \\
\hline C1: Capex & $\sum(\text { Capex })_{i j} x_{i j} \leq C_{\max }$ & Total Capex Limitation \\
C2: Production & $\sum q_{i j} x_{i j} \geq Q_{\min }$ & Production requirement \\
C3: Net Profit & $\sum(\text { Netprofit })_{i j} x_{i j} \geq 0$ & Lowest net profit \\
C4: Capital Control & $(\text { ROCE })_{i j} \geq 2.5 \%$ & Minimum capital efficiency \\
\hline
\end{tabular}


where

$$
H(x)=\left\{\begin{array}{l}
1 \text { if } x \text { is unconventional reservoir } \\
0 \text { if } x \text { is conventional reservoir }
\end{array}\right.
$$

$b_{\text {unconv }}$ is the proportion of unconventional oil and gas in company's long-term plan.

In order to use linear integer programming algorithm to solve this problem, Equation (5) can be linearized as following:

$$
\sum_{j=1}^{m} \sum_{i=1}^{n_{j}}\left[b_{\text {unconv }}-H(x)\right] x_{i j} \leq 0
$$

For a single project in an asset, it may be evaluated based on different scenarios such as different development plans or oil price levels. Only one can be chosen among these evaluation schemes with different economic performances. This constraint is easily written as:

$$
\sum_{l=1}^{3} x_{i j l} \leq 1
$$

where $l$ represents different evaluation scheme, $1 \leq l \leq 3$.

Through different combination of objectives and constraints, more than 300 mathematical models can be presented. A model library was constructed in the software with different models which can give various model combination based on the selection of model and constraints and the necessary input values by the user. The mixed integer programming algorithm and genetic algorithm are used to solve this problem depending on the model is linear or not or if equality constraints exist in this problem. Software is developed with functions like dealing with data file, automatic algorithm selecting based on the nature of the model.

\section{Applications}

The linear integer programing model is conducted for the optimization of 256 overseas projects of SIPC. The typical information of each project is summarized in two tables. Table 3 is the basic information of the project including name, code, contract/block, category et al. Table 4 is the economic evaluation output of each projects.

Normally all the economic evaluation reports and data are stored in MS Excel files. The software developed here can selectively read all the necessary data from these files when they are ready. After that the user need to input all the objectives and constraints and choose some particular options as shown in Figure 2.

Linear integer programing or genetic algorithms are automatically selected based on the combination or model objectives and constraints. For example, when ROCE is selected as an objective, genetic algorithm must be used because the problem is non-linear model. After running the optimization program, optimal combination of projects are given also in an Excel file which contains the values of decision variables, the projects' economic indices and the group indices such as ROCE, PIR, total NPV, total Capex etc. 
Table 3. Project basic information.

\begin{tabular}{ccc}
\hline No. & Parameter & Value \\
\hline A1 & Project Name & Lula \\
A2 & Project code (optional) & PGB.LUL.COM.030 \\
A3 & Contract/Block & BM-S-11 \\
A4 & Project category & Committed \\
A5 & Project maturity type & Pre-gate 3 (FID) \\
A6 & Level of Political Risk & Level 4 of 5 \\
A7 & Level of Reserve & Level 2 of 3 \\
A8 & Operator & Non operated units \\
A9 & Working interest (WI) & $3 \%$ \\
\hline
\end{tabular}

Table 4. Project economic evaluation output.

\begin{tabular}{cccccccccc}
\hline ID & Asset & Project Name & NPV & PIR & UTC & UDC & UOC & Capex & Prod \\
\hline 1 & ADX.NTF & ADX.NTF.EXT.01 & 1169.6 & 0.336 & 52.6 & 44.6 & 18.9 & 7502.4 & 324.8 \\
2 & ADX.3AT & ADX.3AT.COM.01 & 36.8 & 0.854 & 29.9 & 25.0 & 3.1 & 213.1 & 11.2 \\
3 & ADX.3AD & ADX.3AD.NEW.01 & 8.2 & 0.130 & 43.4 & 41.9 & 3.3 & 335.8 & 9.6 \\
4 & ADX.3MB & ADX.3MB.OPT.01 & 1.6 & 0.000 & 22.9 & 17.3 & 10.2 & 121.0 & 0.7 \\
5 & ADX.124 & ADX.124.OPT.01 & 5.3 & 0.917 & 23.4 & 16.5 & 5.2 & 62.3 & 5.8 \\
6 & ADX.4NJ & ADX.4NJ.NEW.01 & 16.2 & 0.486 & 27.3 & 23.4 & 2.2 & 169.9 & 9.0 \\
7 & ADX.126 & ADX.126.EXT.01 & -64.8 & 0.305 & 54.2 & 47.5 & 13.4 & 2314.9 & 79.9 \\
8 & ADX.126 & ADX.126.NEW.11 & 15.3 & 4.461 & 40.6 & 34.9 & 29.3 & 34.4 & 6.5 \\
9 & ADX.126 & ADX.126.NEW.21 & 17.8 & 0.941 & 38.1 & 34.7 & 17.2 & 197.2 & 11.8 \\
10 & ADX.137 & ADX.137.NEW.01 & 81.0 & 0.303 & 28.2 & 25.6 & 7.4 & 1410.0 & 82.5 \\
11 & ADX.137 & ADX.137.OPT.11 & -10.4 & 0.494 & 26.3 & 21.1 & 6.0 & 142.0 & 7.5 \\
12 & ADX.137 & ADX.137.OPT.21 & 8.7 & 0.295 & 32.4 & 26.6 & 5.2 & 196.6 & 8.2 \\
\hline
\end{tabular}

(For saving space and data safety, only 12 projects are listed).

The optimization result in Table 5 shows that 192 projects are selected finally among the total 256 projects. The projects with lower efficiency are removed. And we can find from Table 5 that project ADX.126.EXT.01 with a negative NPV is preserved in the optimization, the reason is that the option "Keep Existing Project" is selected before optimization. So we must note that this is a very strong constraint if it must be claimed by the company's decision-makers.

The production profile and some economic indices before and after optimization are shown in Figure 3 and Figure 4. From the comparison we can find that after optimization even the NPV and Capex decreased to some extent, but the investment efficiency (PIR and ROCE) increased, and also a better accelerated production profile is achieved. 


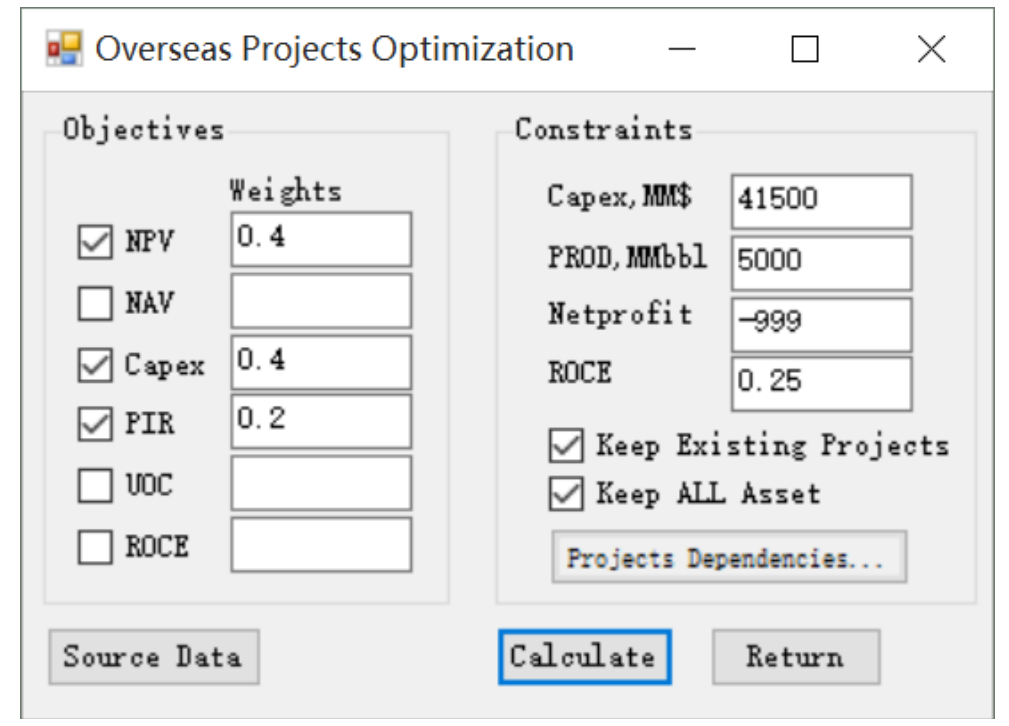

Figure 2. The optimizaiton software main interface.

Table 5. Project optimization result.

\begin{tabular}{cccccc}
\hline Project Name & Selected & NPV & UOC & Capex & Prod \\
\hline ADX.NTF.EXT.01 & 1 & 1169.6 & 18.9 & 7502.4 & 324.8 \\
ADX.3AT.COM.01 & 1 & 36.8 & 3.1 & 213.1 & 11.2 \\
ADX.3AD.NEW.01 & 1 & 8.2 & 3.3 & 335.8 & 9.6 \\
ADX.3MB.OPT.01 & 0 & 1.6 & 10.2 & 121.0 & 0.7 \\
ADX.124.OPT.01 & 1 & 5.3 & 5.2 & 62.3 & 5.8 \\
ADX.4NJ.NEW.01 & 1 & 16.2 & 2.2 & 169.9 & 9.0 \\
ADX.126.EXT.01 & 1 & -64.8 & 13.4 & 2314.9 & 79.9 \\
ADX.126.NEW.11 & 1 & 15.3 & 29.3 & 34.4 & 6.5 \\
ADX.126.NEW.21 & 1 & 17.8 & 17.2 & 197.2 & 11.8 \\
ADX.137.NEW.01 & 1 & 81.0 & 7.4 & 1410.0 & 82.5 \\
ADX.137.OPT.11 & 0 & -10.4 & 6.0 & 142.0 & 7.5 \\
ADX.137.OPT.21 & 1 & 8.7 & 5.2 & 196.6 & 8.2 \\
$\ldots$ & $\ldots$ & $\ldots$ & $\ldots$ & $\ldots$ & $\ldots$ \\
Total & 192 & 28818 & -- & 48897 & 5033 \\
\hline
\end{tabular}

Because of the irreversibility and investment environment complexity of overseas oilfield projects, there is actually no predetermined investment or risk level for a fixed set of projects. The normally adopted mean-variance or semi-variance risk models from modern portfolio theory are not easily realized for practical application, especially for the selection of a large projects group when only deterministic model or information available. To consider the combination risk level of project selection, a weighted risk method is adopted. Each project has some degree of risk in terms of reserve, location, uncertainties in geology and engineering, also the price of oil. So in order to quantitatively evaluate the overall risk of each projects selection, an overall risk formulation if given as following: 


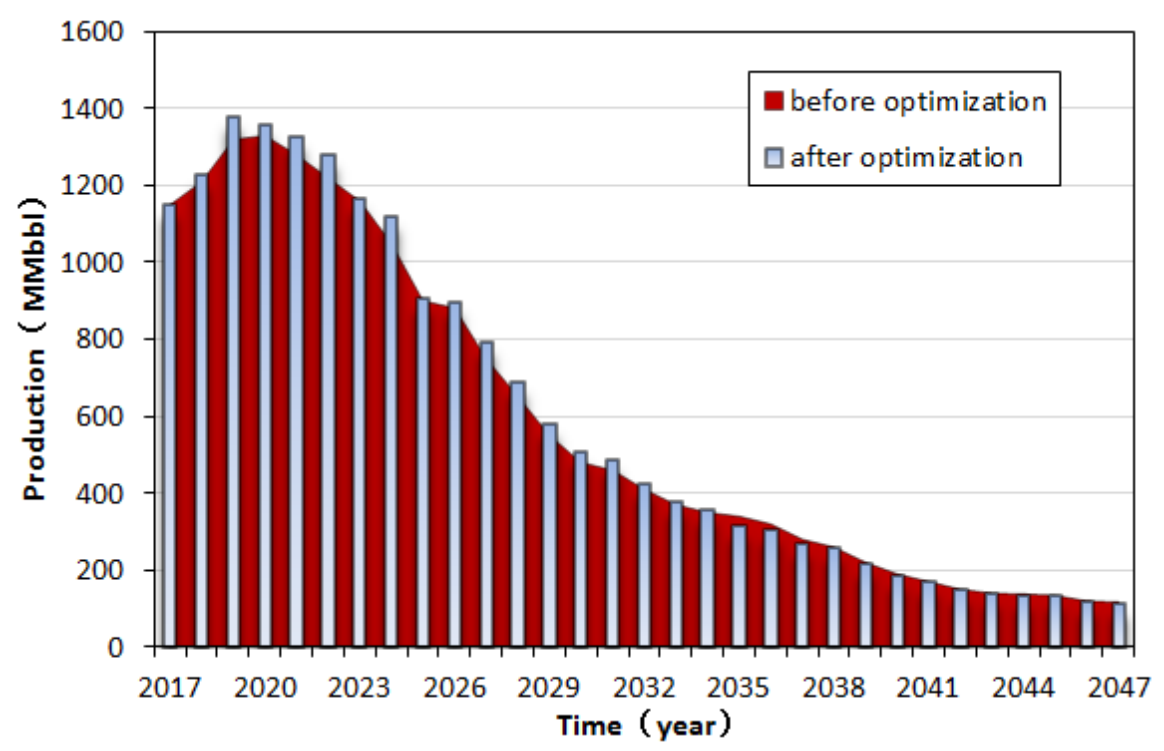

Figure 3. Production profile before and after optimization.
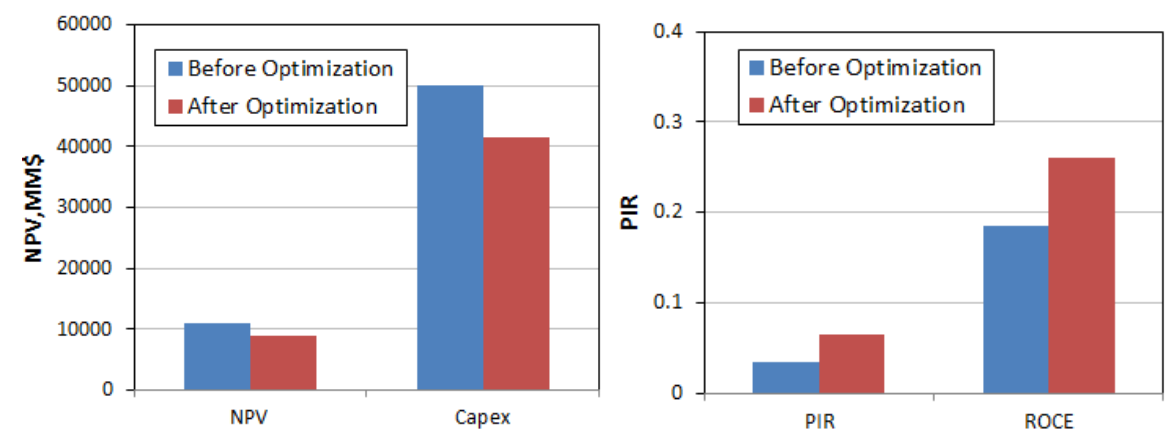

Figure 4. Economic parameters before and after optimization.

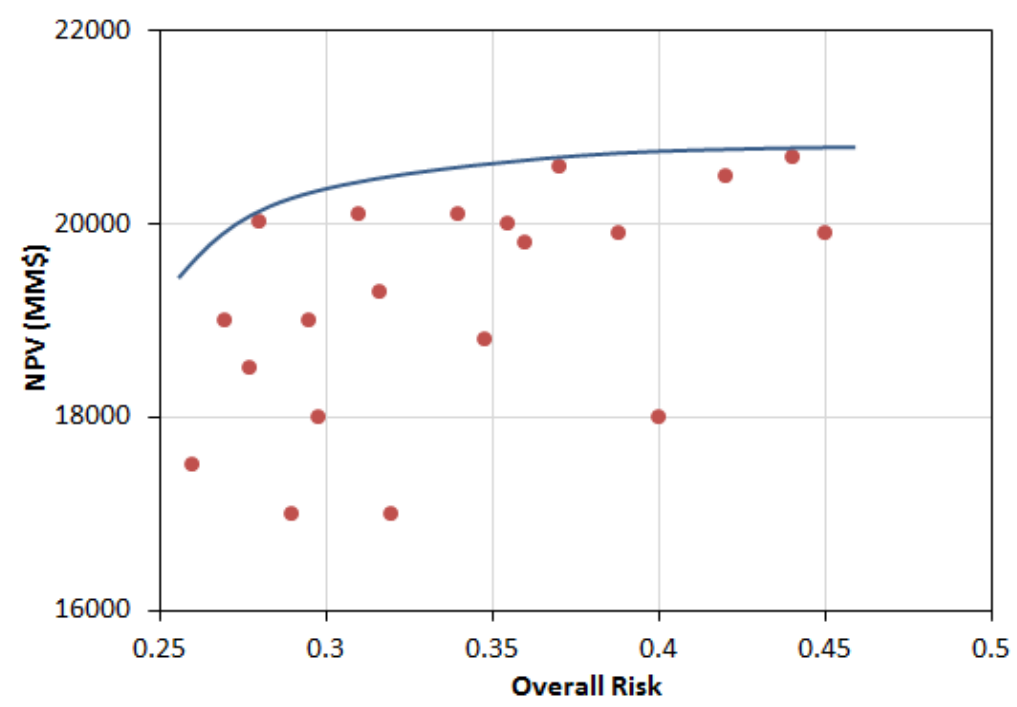

Figure 5. Efficient frontier of the optimization groups.

$$
\operatorname{Risk}_{a}=\operatorname{Risk}_{\text {price }} \cdot K_{1}+\operatorname{Risk}_{\text {reserve }} \cdot K_{2}+\operatorname{Risk}_{\text {politic }} \cdot K_{3}
$$


Equation (9) indicates the overall risk is a combination of risk from oil price, reserve and politics, $K_{1}, K_{2}, K_{3}$ are different weights, $K_{1}+K_{2}+K_{3}=1$. The efficient frontier analysis for different combination schemes is shown in Figure 5.

\section{Conclusion}

The optimal selection of overseas development projects are realized by a mixed integer programming model which based on the available cash flow model evaluation of different projects and assets. Combinations of economic parameters are analyzed and described during the construction of the multi-objective mathematical model. Some practical considerations such as the preservation of existing project or the dependency of assets have great influence on the optimization result. The software developed can give the decision-makers more options in deciding the combination of objectives and constraints, on which the model structure and algorithm will be automatically matched.

\section{Acknowledgements}

Funding for this work was supported by China National Science and Technology Major Project (2016ZX05033005-008). The authors would like to thank overseas research center of Sinopec Institute of Petroleum Exploitation and Development for the case study development.

\section{References}

[1] Aronofsky, J. (1983) Optimization Method in Oil and Gas Development. SPE 12295.

[2] Markowitz, H. (1952) Portfolio Selection. Journal of France, 7, 77-91.

[3] Hightower, M.L. and David, A. (1991) Portfolio Modeling: A Technique for Sophisticated Oil and Gas Investors. SPE Hydrocarbon Economics and Evaluation Symposium, Dallas, TX, 11-12 April 1991, SPE-22016-MS. https://doi.org/10.2118/22016-MS

[4] Orman, M.M. and Duggan, T.E. (1999) Applying Modern Portfolio Theory to Upstream Investment Decision Making. Journal of Petroleum Technology, 51, 50-53. https://doi.org/10.2118/54774-JPT

[5] Campbell, J.M. and Campbell, R.A. (1999) Measuring Strategic Investment Value. SPE Annual Technical Conference and Exhibition, Houston, TX, 3-6 October 1999, SPE-56453-MS. https://doi.org/10.2118/56453-MS

[6] Chron, L.G. (2004) Portfolio Management Framework for Multistage Investments. SPE Annual Technical Conference and Exhibition, Houston, TX, 26-29 September 2004, SPE-90700-MS. https://doi.org/10.2118/90700-MS

[7] Rasey, S.M. (2005) Visualization and Interactive Filtering of Strategy Driven Portfolios as an Alternative to LP Optimization. SPE Hydrocarbon Economics and Evaluation Symposium, Dallas, TX, 3-5 April 2005, SPE-94676-MS. https://doi.org/10.2118/94676-MS

[8] Morteza, P.A. (2010) Project Selection for Oil-Fields Development by Using the AHP and Fuzzy TOPSIS Methods. Expert Systems with Applications, 37, 6218-6224. https://doi.org/10.1016/j.eswa.2010.02.103

[9] Zhong, Y.H. and Zhao, J. (2016) The Optimal Model of Oilfield Development Investment Based on Data Envelopment Analysis. Petroleum, 2, 307-312. 
https://doi.org/10.1016/j.petlm.2016.04.004

[10] Tang, B.J., Zhou, H.L. and Chen, H. (2017) Investment Opportunity in China's Overseas Oil Project: An Empirical Analysis Based on Real Option Approach. Energy Policy, 105, 17-26. https://doi.org/10.1016/j.enpol.2017.02.023 